\title{
Optimizing Configurations: Specifying Combinable Tables
}

\begin{abstract}
Having the right-size tables in a position to be combined with other tables to serve large parties can yield additional revenue at virtually no added cost.
\end{abstract}

\section{BY GARY M. THOMPSON}

$\mathrm{T}$

This article focuses on restaurants with walk-in customers (no reservations are taken), where a host or hostess seats the parties and whcre parties are scated separately. Restaurants of this kind are common in the United States (e.g., TGIF, Chili's, Applebee's). Specifically, this article examines the issue of which tables should be combinable with which orher tables. "Combinability" is the ability to create a larger table from adjacent smaller tables. For example, combinability would allow two adjacent 4-top tables to be combined to seat parties of up eight people. ${ }^{1}$ In an earlier investigation I found that, in many cases, having tables dedicated to specific party sizes was preferable to having combinable tables. ${ }^{2}$ The reason for this was that placing tables on

\footnotetext{
${ }^{1}$ In this paper I assume the conservation of seats for combined tables.

${ }^{2}$ G.M. Thompson, "Optimizing a Restaurant's Seating Capacity: Use Dedicated or Combinable Tables?," Cornell Hotel and Restaurant Administration Quarterly, Vol. 43, No. 3 (August 2002), pp. 48-57.
}

hold, while waiting for customers to depart an adjacent table that can then be combined with the empty on-hold table, imposes a non-productive idle time for the on-hold tables.

In that previous study I assumed a maximum party size of eight people, which allows a restaurant to use tables that seat up to eight customers. Many restaurants, however, serve parties larger than that and have compelling reasons to use combinable tables. For example, when the party sizes get large (such as over 10 people), a restaurant is unlikely to have on hand a single table that is large enough to seat such large parties. Further, for aesthetic reasons, restaurant managers may choose to limit the size of tables to be no larger than a 6- or 8-top. Therefore, the goal of this paper is to identify which tables should be combinable. For example, is it better to be able to combine two 4-tops or a 2-top and a 6-top to seat a party of eight?

○ 2003, CORNELL UNIVERSITY 
I distinguish between the mix of tables in a restaurant - the number of each size table-and the restaurant's configuration-that is, identifying which tables should be easily combined with which other tables. My primary goal for the current investigation is to develop guidelines that can help restaurant managers and designers to configure restaurants. To accomplish my primary objective I had first to investigate several secondary issues, namely:

- Defining restaurant-configuration measurements specifically related to combinable tables; and

- Identifying which configuration measurements are associated with high-performing restaurants.

To address those goals I designed an experiment and used a restaurant-table-simulation model. In this paper I measure performance using the contribution margin per available seat hour (CMPASH) that is delivered by the restaurant based on its ability to seat and process customers. First, though, I review the relevant literature, describe my TABLEMIX restaurantsimulation model, and define restaurantconfiguration measurements. Then I describe the simulation experiment I performed, present the results of that experiment, and close with managerial implications.

\section{Literature Review}

The use of tables in a restaurant is a component of the broader issue of capacity optimizationthat is, seating as many people at one time as possible (given that unrelated parties will be seated separately). "Optimizing capaciry" means using available tables in a way that maximizes profitability. In some of my earlier work I approached capacity optimization from a workforce-scheduling perspective. ${ }^{3}$ Capacity

\footnotetext{
${ }^{3}$ See: G.M. Thompson, "Labor Scheduling Using NPV Estimates of the Marginal Benefit of Additional Labor Capacity," Journal of Operations Management, Vol. 13, No. 1 (July 1995), pp. 67-86; G.M. Thompson, "Labor Scheduling, Part 2: Knowing How Many On-duty Employees to Schedule," Cornell Hotel and Restaurant Administration Quarterly, Vol. 39, No. 6 (December 1998), pp. 26-37; and G.M. Thompson, "Labor Scheduling, Part 3: Developing A Workforce Schedule," Cornell Hotel and Restaurant Administration Quarterly, Vol. 40, No. 1 (February 1999), pp. 86-96.
}

management also has been approached from the perspective of finding the least costly way of delivering a specified level of customer service. ${ }^{4}$

In a restaurant setting, optimizing capacity means structuring the facility in a way that allows profitability to be maximized. In other words, with respect to the table-configuration component of capacity, it means designing the restaurant space that is allocated to tablcs to allow for maximum profitability. ${ }^{5}$

Capacity optimization is related to restaurant revenue management, a topic that has only recently started to receive attention in the academic literature. A series of papers by Kimes and her coauthors first presented a time-based revenueperformance measurement-RevPASH (revenue per available seat hour) - and then followed it with strategies for restaurant revenue management and steps for implementing restaurant revenue management. ${ }^{6}$

A limitation of the RevPASH measure is that it tends to result in revenue maximization, rather than profitability maximization. A better measure of performance than RevPASH would be CMPASH. CMPASH is a more appropriate measure than RevPASH, since CMPASH factors in the variable production costs of menu items. For example, an expensive special may have a high price, which drives RevPASH up, but if it also has a high cost of goods sold, it would have a low contribution margin. Using CMPASH as a performance measure would result in the wait staff's focusing on upselling the most profitable menu items, rather than the most-expensive menu items. The importance of a contribution-based

${ }^{4}$ B. Sill and R. Decker, "Applying Capacity-management Science: the Case of Browns Restaurants," Cornell Hotel and Restaurant Administration Quarterly, Vol. 40, No. 3 (June 1999), pp. 22-30.

${ }^{5} \mathrm{~A}$ broader capacity-management issue is, How much space should be allocated to waiting rooms, back-of-the-house, bar, and other non-seating areas?

${ }^{6}$ See: S.E. Kimes, R.B. Chase, S. Choi, E.N. Ngonzi, and P.Y. Lee, "Restaurant Revenue Management," Cornell Hotel and Restaurant Administration Quarterly, Vol. 40, No. 3 (June 1998), pp. 40-45; S.E. Kimes, D.I. Barrash, and J.E. Alexander, "Developing a Restaurant Revenue-management Strategy," Cornell Hotel and Restaurant Administration Quarterly, Vol. 40, Nn. 5 (Octoher 1999), pp. 18-30; and S.E. Kimes, "Implementing Restaurant Revenue Management: A Five-step Approach," Cornell Hotel and Restaurant Administration Quarterly, Vol. 40, No. 3 (June 1999), pp. 16-21. 
measure of performance has been recognized previously, ${ }^{7}$ but clearly the need is for a time-based measure such as CMPASH.

I am aware of only three papers addressing the issue of restaurants' table-mix optimization. Sherri Kimes and I examined the mix of table sizes for a specific mid-scale, full-service restaurant. ${ }^{8}$ Compared to that restaurant's pre-study table mix, we found that the restaurant's ideal table mix would allow it to process 50 percent more customers without increasing customers' waiting time. In a follow-up paper, Kimes and I presented and evaluated a variety of quantitative techniques for identifying the ideal table mix in restaurants. ${ }^{9}$ We found that a modified version of the simple method which I presented in my earlier table-optimization paper typically performs well. ${ }^{10}$

In a recent paper I examined the issue of table combinability in restaurants like those I consider in this paper. ${ }^{11}$ Though I found that dedicated tables were better for a 200-seat restaurant and for a 50-seat restaurant with a large average party size, there are times when tables should be combinable. This current paper thus extends my earlier research by looking at which tables should be easily combined with which other tables.

\section{TABLEMIX Simulation Model}

A key tool in this investigation was the TABLEMIX simulation model. ${ }^{12}$ TABLEMIX models restaurant-table use under a wide variety of conditions that can be controlled by manag-

\footnotetext{
${ }^{7}$ B. Quain, M.W. Sansbury, and S.M. LeBruto, "Revenue Enhancement, Part 4-Increasing Restaurant Profitability," Cornell Hotel and Restaurant Administration Quarterly, Vol. 40, No. 3 (June 1999), pp. 38-47.

${ }^{8}$ S.E. Kimes and G.M. Thompson, "Restaurant Revenue Management at Chevys: Determining the Best Table Mix," working paper, School of Hotel Administration, Cornell University, 2002.

${ }^{9}$ S.E. Kimes and G.M. Thompson, "A Comparison of Techniques for Identifying Optimal and Near-optimal Restaurant Table Mixes," working paper, School of Hotel Administration, Cornell University, 2002.

${ }^{10}$ Thompson, 2002; op. cit.

$"$ Thompson, 2002; op. cit.

${ }^{12}$ Thompson, G. M. and R. Verma, "Computer Simulation in Hospitality Teaching, Practice and Research." Forthcoming in the Cornell Hotel and Restaurant Administration Quarterly, 2003.
}

ers. The model assumes that the time between party arrivals is exponentially distributed $;^{13}$ that the space occupied by a table is proportional to the number of its seats; and that parties are not combined at tables (so, for example, two separate two-person parties would not be seated together at a 4-top).

TABLEMIX's inputs are the length of the dining time one wishes to simulate; the number of parties one expects to arrive during the dining period (at 15-minute intervals); the number of

\section{In this paper I measure performance using the contribution margin per available seat hour-a better gauge of profitability than revenue per available seat hour.}

days one wishes to simulate; the probabilities of different size parties; the maximum number of waiting parties; the distribution of dining durations (normal or log-normal); and the tableassignment rule (assign an available table to the largest party or to the party waiting the longest). TABLEMIX inputs that are specified for each size party are the mean and standard deviation of dining time by party size, the maximum wait the party will tolerate, and the party's revenue (or contribution value).

Outputs of the TABLEMIX model are the average wait by party size, the number and value of customers served and lost, the use of each size table by 15 -minute periods, and seat use by 15-minute periods.

TABLEMIX evolved from a simulation model I originally developed for use by my students at Cornell University's School of Hotel Administration. In a teaching context, I use a basic version of TABLEMIX to illustrate concepts of simulation and process design (bottleneck analysis) in a restaurant setting. The teaching version does not allow tables to be combined, nor does it find the best mix of tables; rather it simply simulates the performance of a user-specified table mix.

\footnotetext{
${ }^{13}$ This is actually a very common situation in practice. What it means is that there is a higher likelihood of parties arriving close together in time, but a lower likelihood of there being a long time between party arrivals.
} 


\section{Table Combinability: Vital Measurements}

To help describe the measurements, Exhibit 1 illustrates two different configurations of a 50-seat restaurant that has the same mix of tables. Combinable tables are linked by lines. For example, in Configuration 1 tables 16 and 17 can be combined to make a 4-top. Both configurations have a 50 -percent combinability level. ${ }^{1}$

Mean chain length (CLM). This measurement assesses the extent to which a series of tables can be combined. I define a "chain" as a series of adjacent tables that can be combined. For example, consider tables 11,12 , and 13 in Configuration 1 . Since those tables are all combinable, a chain may comprise tables 11-12-13. Subchains would be tables 11-12 and tables 12-13. The table chain of 11-12-13 would have a length of 3 , since it comprises three component tables. Configuration 1 in Exhibit 1 has four chains: 3-4-5 (length 3), 8-9 (length 2), 11-12-13 (length 3 ), and 16-17 (length 2 ). The mean chain length for this configuration is 2.5 tables: $(3+2+3+2) \div 4$.

Standard deviation of chain lengths (CLSD). This measurement tracks the variability of chains. Using Configuration 1, the CLSD is 0.5 tables: $\left\{\left[\left((3-2.5)^{2}+(2-2.5)^{2}+(3-2.5)^{2}+(2-2.5)^{2}\right) \div 4\right]^{0.5}\right\}^{2}$

Mean chain seats (CSM). This is another measurement designed to capture the extent to which a series of tables can be combined. From Configuration 1 , the four chains comprise a total of six seats $(2+2+2$, for tables $3-4-5)$, four seats $(2+2$, for tables 89$)$, twelve seats $(4+6+2$, for tables 11-12-13) and four seats ( $2+2$, for tables 16-17). CSM, then, equals 6.5 seats: $(6+4+12+4) \div 4$.

Standard deviation of chain seats (CSSD). Similar to CLSD, this is another measurement of chain variability, though this measurement calculates the variation in the number of seats per chain. Configuration 1 in Exhibit 1 would have a CSSD of 3.28 seats $\left\{\left[\left((6-6.5)^{2}+(4-6.5)^{2}\right.\right.\right.$ $\left.\left.+(12-6.5)^{2}+(4-6.5)^{2}\right) \div 4\right]^{0.5}$.

Mean table size difference within chains (TSDM). This measurement is designed to assess the extent to which the chains comprise similar- or dissimilar-size tables. It is calculated from the absolute value of the difference in seating capacity between adjacent combinable tables. For example, in Configuration 1, combinable adjacent table pairs are $3-4,4-5,8-9,11-12,12-13$, and 16-17. The difference in table sizes within these tables pairs are $0,0,0,2,4$, and 0 seats, respectively. Thus, TSDM is 1.0 seats: $(0+0+0+2+4+0) \div 6$.

Standard deviation of table-size differences within chains (TSDSD). This measurement determines the extent to which adjacent combinable tables have consistent differences in size. Using Configuration 1, TSDSD is 1.53 seats: $\left\{\left[\left((0-1)^{2}+(0-1)^{2}+(0-1)^{2}+(2-1)^{2}+(4-\right.\right.\right.$ $\left.\left.1)^{2}+(0-1)^{2}\right) \div 6\right]^{0.5}$.

Unique seat count from chains and subchains (USC). This measurement calculates the number of unique table sizes that can be created from the chains and subchains of the combinable tables. For ex ample, Configuration 1 has five unique table sizes that can be created from the combinable tables: four seats (from tables 3-4, 4-5, 8-9, and 16-17), six seats (from tables 3-4-5), eight seats (from tables 12-13), ten seats (from tables 11-12), and twelve seats (from tables 11-12-13).

Chain and subchain count (CSC). CSC counts the total number of chains and subchains that are created from the combinable tables. It represents a measurement of the total flexibility offered by the combinable tables. Configuration 1 has a total of eight chains and subchains (tables 3-4, 3-4-5, 4-5, 8-9, 11-12, 11-12-13, 12-13, and 16-17).

Exhibit 2 scores the two configurations from Exhibit 1 using the configuration measurements identified above. Configuration 2 scores higher on all measurements because it has more total seats for the combinable tables, a larger maximum chain length, and more variability in the sizes of the combinable tables.-G.M.T.

\footnotetext{
${ }^{1}$ As defined in: Thompson, 2002; op. cit.

${ }^{2}$ For this formula (and others in the paper) I am using the formula for the population standard deviation (not the sample standard deviation), since I am using the entire population of chains within the configuration.
}

\section{EXHIBIT 1}

\section{Sample configurations for a 50-seat restaurant}
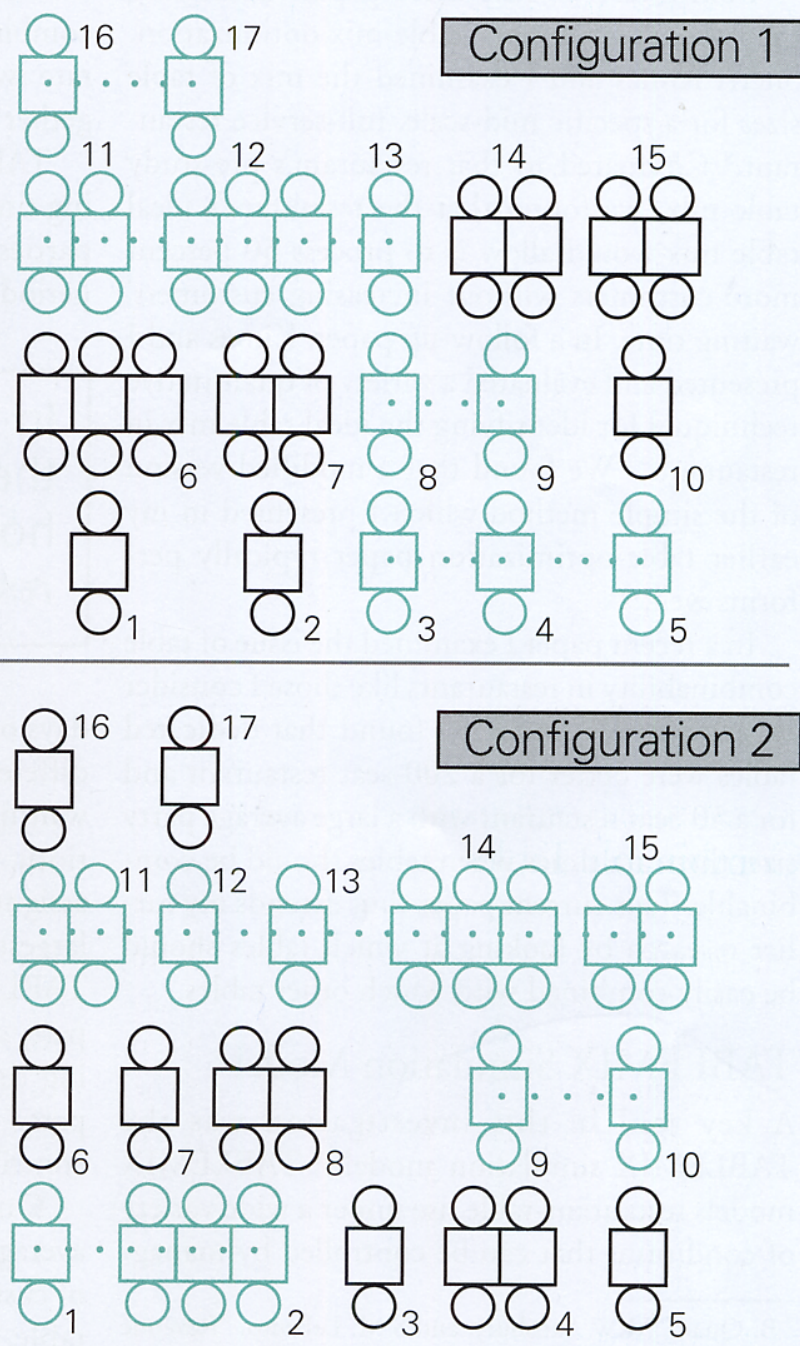

In both examples above, the restaurant comprises eleven 2-tops, four 4 -tops and two 6-tops. Combinable tables are linked by lines.

\section{EXHIBIT 2}

\section{Scoring the configurations from Exhibit 1} (above) using the configuration measurements

\begin{tabular}{lc|c|c} 
Exhibit 1 configurations: & & $\mathbf{1}$ & $\mathbf{2}$ \\
\hline Configuration measure- & CLM & 2.5 tables & 3.0 tables \\
ments (as described in & CLSD & 0.5 tables & 1.41 tables \\
the text on this page) & CSM & 6.5 seats & 10.0 seats \\
& CSSD & 3.28 seats & 5.89 seats \\
& TSDM & 1.0 seats & 2.0 seats \\
& TSDSD & 1.53 seats & 1.63 seats \\
& USC & 5 sizes & 7 sizes \\
& CSC & 8 chains & 12 chains \\
\hline
\end{tabular}




\section{EXHIBIT 3}

Probability of different-size parties, under the two levels of party-size range

\begin{tabular}{c|c|c}
$\begin{array}{c}\text { Party } \\
\text { size }\end{array}$ & \multicolumn{2}{|c}{ Party-size range } \\
$\mathbf{1}$ to $\mathbf{9}$ & $\mathbf{1}$ to $\mathbf{1 2}$ \\
\hline 1 & 0.23 & 0.2900 \\
2 & 0.43 & 0.4000 \\
\hline 3 & 0.15 & 0.1200 \\
4 & 0.10 & 0.0900 \\
\hline 5 & 0.04 & 0.0350 \\
6 & 0.02 & 0.0200 \\
\hline 7 & 0.01 & 0.0125 \\
8 & 0.01 & 0.0100 \\
\hline 9 & 0.01 & 0.0075 \\
10 & 0.00 & 0.0075 \\
\hline 11 & 0.00 & 0.0050 \\
12 & 0.00 & 0.0025 \\
\hline Average & 2.50 & 2.5000
\end{tabular}

\section{Measurements Related to Combinable Tables}

To evaluate the effect of combinable tables on a restaurant's capacity, one first must be able to measure different aspects of a restaurant's seating configuration(s). Specifically, I identified eight measurements, which are described in the box on the facing page. My measurements assume that the restaurant tables are set up in rows and that tables can be combined within rows but not across rows.

\section{Experimental Design}

The particular restaurant environment in which I conducted the simulation study of restaurant configurations was based somewhat on the Chevys restaurant that Sherri Kimes and I reported on in our earlier study. ${ }^{16}$ For the current study, however, I modified the environment as I deemed necessary to create a broadly applicable study.

The simulation experiment had two factors: party-size range (two levels) and allowed table size (two levels). Party sizes ranged from one to nine people and from one to twelve people in the two levels, and followed the probability dis-

\footnotetext{
${ }^{16}$ Kimes and Thompson, "Restaurant Revenue Management at Chevys: Determining the Best Table Mix," op. cit.
}

\section{EXHIBIT 4}

Party-arrival rates, at 15 -minute intervals

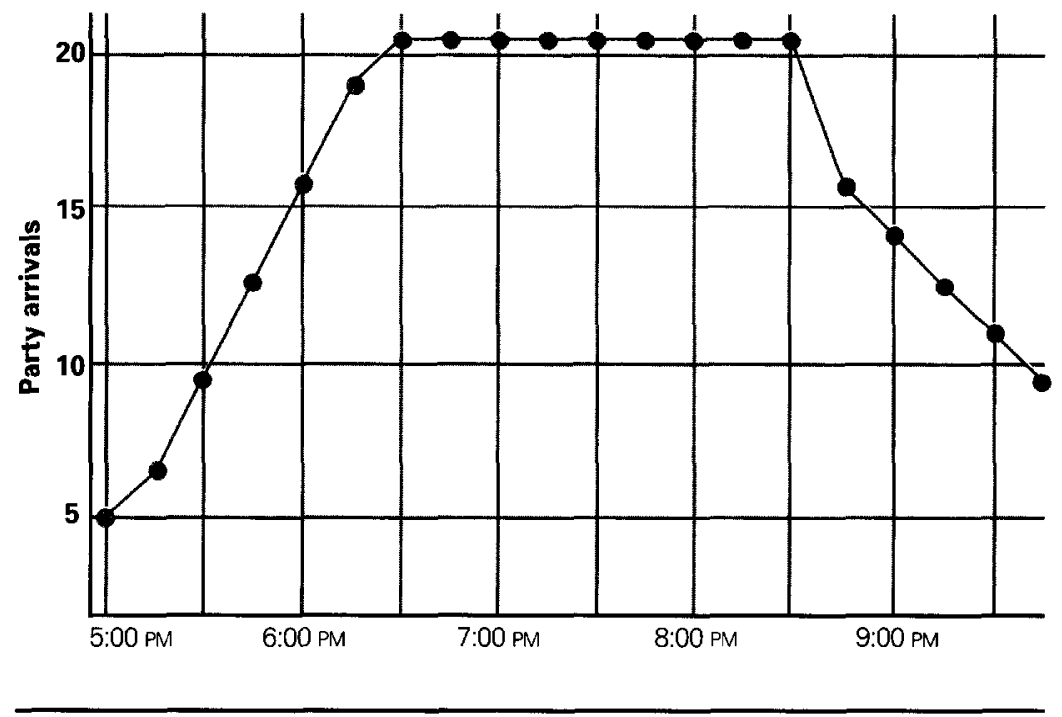

tributions shown in Exhibit 3. The probabilities for the party size range of one to nine people are from an actual restaurant. ${ }^{17} \mathrm{I}$ modified those data to create the probabilities for party sizes of one to twelve, so that the mean party size would remain the same, at 2.5 people.

One level of table sizes allowed the use of 2-tops, 4-tops, and 6-tops, while the other allowed the use of 2-tops, 4-tops, 6-tops, and 8 -tops. Since I simulated a 200 -seat restaurant, there are a total of 884 unique table mixes using only 2-tops, 4-tops, and 6-tops, while there are a total of 8,037 unique table mixes using 2-, 4-, 6- and 8-tops.

I created party-arrival rates that would result in the restaurant experiencing a seat utilization of 95 percent during the peak period of customer arrivals, as illustrated in Exhibit 4. Since achieving a seat utilization beyond 85 percent tends to be impractical for the kind of restaurants I am examining, the 95-percent level represents a situation where the restaurant is most likely losing customers because of insufficient capacity (i.e., the restaurant is unable to satisfy all customer demand) and so it is designed to highlight any differences in configurations.

${ }_{17} \mathrm{Ibid}$ 


\section{EXHIBIT 5}

Stepwise-regression-model results, by factor-level category

\begin{tabular}{|c|c|c|c|c|c|}
\hline & \multirow{2}{*}{$\frac{\text { Party size }}{\text { Table sizes }}$} & \multicolumn{2}{|c|}{1 to 9} & \multicolumn{2}{|c|}{1 to 12} \\
\hline & & $2,4,6$ & $2,4,6,8$ & $2,4,6$ & $2,4,6,8$ \\
\hline \multirow{8}{*}{ 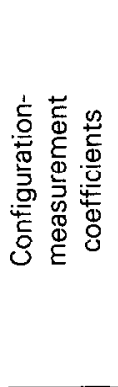 } & CLM & 37.676 & 34.501 & $19.456^{*}$ & 36.949 \\
\hline & CLSD & & -9.903 & -59.073 & \\
\hline & $\mathrm{CSM}$ & -17.601 & -15.399 & -16.843 & -13.056 \\
\hline & $\operatorname{CSSD}$ & -5.443 & -3.925 & & $-1.608^{*}$ \\
\hline & TSDM & 6.921 & 10.449 & 9.026 & 5.675 \\
\hline & TSDSD & 31.072 & 24.880 & & 33.452 \\
\hline & USC & & 0.624 & $1.034^{*}$ & 1.174 \\
\hline & $\csc$ & 1.038 & 0.925 & 2.935 & \\
\hline \multicolumn{2}{|c|}{ Full-model $R^{2}$} & 0.7982 & 0.8493 & 0.5856 & 0.6702 \\
\hline \multicolumn{2}{|c|}{ Full-model Adj $\mathrm{R}^{2}$} & 0.7959 & 0.8478 & 0.5814 & 0.6672 \\
\hline \multicolumn{2}{|c|}{ Table-mix-only $\mathrm{R}^{2}$} & 0.7666 & 0.8213 & 0.5793 & 0.6457 \\
\hline \multicolumn{2}{|c|}{ Table-mix-only Adj $\mathrm{R}^{2}$} & 0.7643 & 0.8195 & 0.5751 & 0.6426 \\
\hline \multicolumn{2}{|c|}{$\begin{array}{l}\mathrm{R}^{2} \text { Increase from } \\
\text { configuration } \\
\text { measurements }\end{array}$} & 0.0316 & 0.0280 & 0.0063 & 0.0245 \\
\hline
\end{tabular}

\section{Notes:}

$\mathrm{CLM}=$ mean chain length, in tables;

CLSD = chain length standard deviation, in tables:

$\mathrm{CSM}=$ mean chain seats;

CSSD = standard deviation of chain seats;

TSDM = mean absolute difference in sizes of adjacent combinable tables;

TSDSD = standard deviation of size differences of adjacent combinable tables:

USC $=$ number of unique table sizes from chains and subchains; and

$\mathrm{CSC}=$ number of chains and subchains.

Unless otherwise noted, coefficients are significant at the 0.001 level.

* $p<0.01$
In my earlier investigation I examined the issue of table combinability by including an experimental factor for the level of combinability. ${ }^{18}$ In the current paper I use a 50-percent table combinability level. As an example, the two restaurant configurations in Exhibit 1 both have a 50 -percent combinability level. In that earlier investigation I (1) enumerated all possible table mixcs for cach size restaurant and (2) randomly selected one possible configuration of the restaurant for each table mix. However, the set of possible configurations is large, based on which tables are combined with which other tables. For example, Exhibit 1 illustrates two possible configurations for a 50-seat restaurant with a table mix of eleven 2-tops, four 4-tops, and two 6-tops.

Since my goal in this paper is to identify the characteristics of best-performing configurations, I first simulated one randomly selected configuration for each possible table mix. I then selected the best 50 of the 2-4-6 table-size scenario (or about 5.6 percent of the toral) and the best 200 of the 2-4-6-8 table-size scenario (or about 2.5 percent of the total). For example, with party sizes ranging from one to nine and table sizes of 2-46 , the best-performing mix of the 884 alternatives had forty-five 2-tops, twenty 4-tops, and five 6-tops. For each of the best-performing table mixes, I randomly generated 100 different configurations and simulated the restaurant performance. In doing so, I was able to control for the influence of table mix and isolate the effects due to the actual configuration of the restaurant.

For this investigation I made the following assumptions: a 55-minute mean dining time for all parties; a lng-normal distribution of dining times; ${ }^{19}$ a $\$ 10$-per-person contribution value for all parties; a maximum tolerable wait of 90 minutes for all parties; a table-assignment rule that assigned available tables to the largest waiting party; simulating 150 days of operation (equivalent to about 1.5 year's worth of operation, where there were two peak days per week); that no more than 40 parties could be waiting at any one time; and that tables would be combined only for par-

\footnotetext{
${ }^{18}$ Thompson, 2002.

${ }^{19}$ Log-normal distributions of service times occur quite commonly in restaurants. Log-normal distributions look much like a normal distribution, except that one tail is elongated.
} 
ties larger than six. I also only collected data after the simulated restaurant had been operating for 90 minutes each day (this ensured that it was in its peak period, as can be seen from Exhibit 4).

\section{Results}

In analyzing the results, I used least-squares linear regression, as described in the sidebar on this page. Exhibit 5 presents the results of running a stepwise least-squares linear regression on schedule profitability as a function of restaurant configuration (using the configuration measurements presented earlier), while controlling for the specific table mix. Only those statistically significant predictor variables are included in the table. Exhibit 5 also includes the $\mathrm{R}^{2}$ and adjusted $\mathrm{R}^{2}$ for the regression models.

Unless otherwise indicated, the variable coefficients in Exhibit 5 are statistically significant at the 0.001 level. Since the dependent variable was in dollars, the coefficients are in dollars. So, for example, increasing the mean chain length by one table, where party sizes ranged from one to nine people and tables had two, four, and six seats would increase daily restaurant contribution by $\$ 37.68$, assuming all other variables remained unchanged.

As a way to judge the relative explanatory ability offered by the configuration measurements, I also developed stepwise least-squares linear tegression models that only included the table-mix coding variables. The $\mathrm{R}^{2}$ and adjusted $\mathrm{R}^{2}$ for these regression models are also included in Exhibit 5. By subtracting the adjusted $R^{2}$ for the table-mixonly model from the adjusted $\mathrm{R}^{2}$ for the complete regression model, I arrived at a measurement of the explanatory ability of the restaurant configuration. The greatest explanatory power of the restaurant configuration occurred with a party-size range of one to nine, and the lowest occurred with a party-size range of one to twelve, using 2-top, 4-top, and 6-top tables.

Exhibit 6 shows the mean restaurant contribution by experimental-factor levels. It also shows the range in contribution predicted by the linear regression equations. For example, with party sizes ranging from one to nine and using 2-top, 4-top, and 6-top tables, the best restaurant configuration generated $\$ 74.48$ more contribution than the worst restaurant configuration (as pre-

\section{Different Restaurant Configurations: The Effects}

The contribution of the $\mathrm{j}^{\text {th }}$ restaurant configuration having the $\mathrm{i}^{\text {th }}$ table mix is given by:

$$
\begin{aligned}
& \text { Contribution }_{i j}= \\
& \beta_{i}^{M i x}+\beta^{C L M} \times C L M_{i j}+\beta^{C L S D} \times C L S D_{i j}+\beta^{C S M} \times \\
& C S M_{i j}+\beta^{C S S D} \times C S S D_{i j}+\beta^{T S D M} \times T S D M_{i j}+\beta^{T S D S D} \\
& \times T S D S D_{i j}+\beta^{U S C} \times U S C_{i j}+\beta^{C S C} \times C S C_{i j}+\varepsilon_{i j}
\end{aligned}
$$

where:

$$
\begin{aligned}
& \beta_{i}^{\text {Mix }}=\text { contribution coefficient for table mix } i \\
& \beta^{C L M}=\text { contribution coefficient for the mean chain length } \\
& C L M_{i j}=\text { mean chain length for restaurant configuration } j \text { for table mix } i \\
& \beta^{C L S O}=\text { contribution coefficient for the chain length standard deviation } \\
& C L S D_{i j}=\text { chain length standard deviation for restaurant configuration } j \\
& \text { for table mix } i \\
& \beta^{C S M}=\text { contribution coefficient for the mean chain seats } \\
& C S M_{i j}=\text { mean chain seats restaurant configuration } j \text { for table mix } i \\
& \beta^{C S S D}=\text { contribution coefficient for the standard deviation of chain } \\
& \text { seats } \\
& C S S D_{i j}=\text { standard deviation of chain seats restaurant configuration } j \\
& \text { for table mix i } \\
& \beta^{\text {TSDM }}=\text { contribution coefficient for the mean absolute difference in } \\
& \text { seats of adjacent combinable tables } \\
& T S D M_{i j}=\text { mean absolute difference in seats of adjacent combinable } \\
& \text { tables for restaurant configuration } j \text { for table mix } i \\
& \beta^{\text {TSOSD }}=\text { contribution coefficient for the standard deviation of the } \\
& \text { differences in seats of adjacent combinable tables } \\
& T S D S D_{i j}=\text { standard deviation of differences in seats of adjacent } \\
& \text { combinable tables for restaurant configuration } j \text { for table mix } i \\
& \beta^{\text {USC }}=\text { contribution coefficient for the count of unique table sizes } \\
& \text { from chains and subchains } \\
& U S C_{i j}=\text { count of unique table sizes from chains and subchains for } \\
& \text { restaurant configuration } j \text { for table mix } i \\
& \beta^{C S C}=\text { contribution coefficient for the count of chains and subchains } \\
& C S C_{i j}=\text { count of chains and subchains restaurant configuration } j \\
& \text { for table mix } i \\
& \varepsilon_{i j}=\text { error coefficient for restaurant configuration } j \text { for table mix } i
\end{aligned}
$$

The first term of the regression equation is a coding variable to capture the effect associated with the particular table mix.-G.M.T. 
EXHIBIT 6

\section{Predicted contribution range from restaurant con-} figuration and mean restaurant contribution, by level of the experimental factors

\begin{tabular}{c|c|c|c|c}
$\begin{array}{c}\text { Table } \\
\text { Size }\end{array}$ & $\begin{array}{c}\text { Table } \\
\text { sizes }\end{array}$ & $\begin{array}{c}\text { Mean } \\
\text { contribution }\end{array}$ & $\begin{array}{c}\text { Range in predicted } \\
\text { contribution from } \\
\text { configuration }\end{array}$ & $\begin{array}{c}\text { contribution from } \\
\text { configuration as a } \\
\text { percent of mean } \\
\text { contribution }\end{array}$ \\
\hline 1 to 9 & $2,4,6$ & 5734.73 & 74.48 & 1.30 \\
& $2,4,6,8$ & 5719.20 & 78.84 & 1.38 \\
\hline 1 to 12 & $2,4,6$ & 5644.50 & 68.14 & 1.21 \\
& $2,4,6,8$ & 5633.25 & 62.57 & 1.11 \\
\hline
\end{tabular}

${ }^{1}$ This is the difference between the highest and lowest predicted contribution effects from restaurant configurations.

${ }^{2}$ For example, $74.48 \div 5,734.73 \times 100$ percent $=1.30$ percent

\section{Seven Steps to Enhanced Profitability Using Table-capacity Optimization}

1. Identify peak periods during the week.

2. Using data from POS (supplemented perhaps with data from time studies), identify probabilities of different-size parties and the dining duration by party size for the peak dining periods, and estimate the contribution margin by party size.

3. Identify a table mix that provides a good match between capacity and customer demand during the peak periods, ${ }^{1}$ and that meets any company policy on maximum table sizes.

4. Have a restaurant designer develop alternative configurations that come as close as possible to the ideal table mix. The designer should be instructed to create the longest possible series of variable-size combinable tables.

5. Simulate the alternative configurations to see how they perform.

6. Pick the best configuration and implement it.

7. Be prepared to adjust front- and back-of-the-house labor and work methods to support the increased table capacity.-G.M.T.

\footnotetext{
${ }^{1}$ See, for example: Thompson, 2002, op. cit.; and Kimes and Thompson, "A Comparison of Techniques for Identifying Optimal and Near-optimal Restaurant Table Mixes," op. cit.
}

Gary M. Thompson, Ph.D. is an associate professor of operations management at the Cornell University School of Hotel Administration (gmt1@cornell.edu).

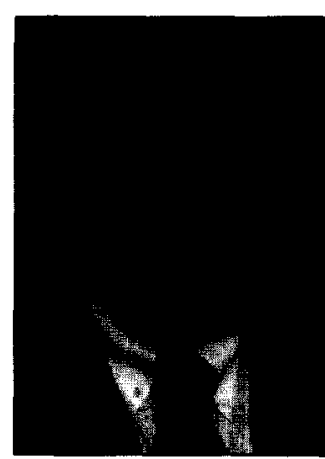

dicted by the regression equation). This $\$ 74.48$, which is approximately equivalent to serving three additional parties per day (at the average size of 2.5 people), represents 1.3 percent of the mean daily contribution of $\$ 5,734.73$ for restaurants with these experimental factor levels. The predicted contribution attributable to restaurant configuration ranged from 1.1 to almost 1.4 percent.

\section{Managerial Implications}

The results in Exhibits 5 and 6 indicate that getring the right table mix is of paramount importance (based on the variation explainedthe adjusted $\mathrm{R}^{2}$ - by the complete regression model compared to that explained by the model using only the table-mix coding).

Nonetheless, restaurant configuration does matter, since identifying a good restaurant configuration can improve contribution by about 1.1 - to 1.4-percent over a poor configuration. Since a good configuration can be identified with little additional effort beyond that required to identify the best table mix, there is a high benefit for the minimal cost.

Looking at my overall findings, some general guidelines become apparent. In general, restaurants should be constructed as follows:

(1) With relatively long table chains. For example, a chain of 2-top/4-top/6-top/ 2-top tables would be preferable to two separate chains of 2-top/4-top tables and 6-top/2-top tables.

(2) With smaller, rather than larger, combinable tables. For example, a chain of 2-top/4-top/6-top tables would be preferable to a chain of 4-top/4-top/ 6-top tables.

(3) With relatively large size differences between adjacent combinable tables. For example, a chain of 2-top/4-top/2-top/ 6-top tables would be superior to a chain of 2-top/2-top/4-top/6-top tables.

The spccific bencfits will vary by the range of party sizes and the size of tables one allows. Putting the findings in context, however, it is important to realize that a good configuration cannot overcome a poor table mix. The greatest benefits will be achieved by using a good configuration and a good table mix. 